\title{
Impact of Incision on Outcome in Composite Resections of Oral Cancer
}

\author{
Arun Holenarasipur Narasannaiah', Ramesha K T² \\ ${ }^{1}$ Assistant Professor, Department of Surgical Oncology, Kidwai Cancer Institute, Bangalore, ${ }^{2}$ Prof \&Head, Department of Plastic Surgery, BMC\&RI, \\ Bangalore.
}

\section{Abstract}

Background: Various surgical approaches have been described for resection of oral cancers based on the subsite, extent of the disease, extent of resection needed and the presence of metastatic lymph nodes neccesiating neck dissection. The goal in the management of oral cancer is to cure loco regional disease with preserving near normal functional and cosmetic outcome with adequate surgical approach. Subjects and Methods: We did a retrospective analysis of 105 Head and Neck cases that presented in Surgical Oncology outpatient services at Department of General surgery, Bangalore Medical College and Research Institute between July 2015 to February 2019. Out of thes, 90 cases were oral cancers which were investigated with biopsy, imaging and Staging was done. There were 65 cases which were considered operable included in this study. Details regarding the Diagnosis, Subsite, Extent and Stage were noted down. Results: Among the various Surgical incisions used for Oral cancer composite resection in 38 cases, Shoebeinger's incision remained the most common approach used in 26 cases. 4 cases underwent with lateral utility, and Visor flap. The 8 cases done with Modified Shoebeinger incision, wherein the vertical component is replaced by lower skin crease curvilinear horizontal modification. There were 24 segmental mandibulectomies, 3 Bite Resection with segmental mandibulectomies and 3 cases of Marginal mandibulectomies done with shoebingers incision, similarly 6 cases, 1 and 1 respectively done with modified shoebinger's incision. Conclusion: Surgery is the mainstay of treatment for local and locally advanced operable oral Cancer in all the subsites.

Keywords: Composite Resections, Oral Cancer, Impact of Incision.

Corresponding Author: Dr. Arun Holenarasipur Narasannaiah, Assistant Professor, Department of Surgical Oncology, Kidwai Cancer Institute, Bangalore.

Received: December 2019

Accepted: December 2019

\section{Introduction}

Globally over three lakh people are diagnosed with oral cancer each year and it is the eighth most common malignancy in the world. ${ }^{[1]}$ In India, the incidence of oral cancer is 12.6 per one lakh population. ${ }^{[2]}$ The high incidence rates are related to widespread habit of tobacco chewing by both males and females.

Surgery is the primary modality of treatment in oral cancer,with chemotherapy and radiotherapy having an adjuvant role in locally advanced disease. ${ }^{[3]}$ Various surgical approaches have been described for resection of oral cancers based on the subsite, extent of the disease, extent of resection needed and the presence of metastatic lymph nodesneccesiating neck dissection. ${ }^{[4]}$ The goal in the management of oral cancer is to cure loco regional disease with preserving near normal functional and cosmetic outcome with adequate surgical approach. This study aims at analyzing the various surgical incisions to oral cancer and their outcomes with respect to Oncological cure and bettercosmesis.

\section{Subjects and Methods}

This We did aretrospective analysis of 105 Head and Neck cases that presented in Surgical Oncology outpatient services at Department of General surgery, Bangalore Medical College and Research Institute between July 2015 to February 2019.Out of these , 90 cases were oral cancers which were investigated with biopsy, imaging and Staging was done. There were 65 cases which were considered operable included in this study.Details regarding the Diagnosis, Subsite, Extent and Stage were noted down. The type of Surgical incisions for resection of primary and neck dissection with or without reconstruction were recorded. The post-operative recovery including, Histopathology, wound healing, functional outcome, cosmesis and complications were noted down. Wherever adjuvant chemoradiotheraphy is indicated, patients underwent within 4-6 weeks postoperative period. The patients were followed up periodically upto 12 months postoperatively along with rehabilitation. 


\section{Result}

Out of 65 cases that were included in this study, 39 (60\%) were females and $26(40 \%)$ were males. The age group of our patients ranged from 29 years to 78years, of which 4150 years (20 patients) was the most commonest age at presentation. Before the age of $50 \mathrm{yrs}$ there was male preponderance, however above 50 years females were common.

In our observation, the common site of oral cancer is GingivobuccalSulcus seen among 31 patients (34.4\%),followed by $15(16.6 \%)$ cases of Bucccal mucosa, 14(15.5\%) cases of Cancer alveolus and others being tongue cancer $7(7.7 \%)$, RetromandibularTrigone3(3.3\%), Floor of mouth $2(2.2 \%)$, palate $3(3.3 \%)$ and $\operatorname{Lip} 3(3.3 \%)$.

Among 65 cases of operable oral cancers 38 cases underwent composite resection with Comprehensive neck dissection, are taken for analysis in this study. Around 16cases underwent wide excision with Neck dissection and 11 cases underwent only wide excision.. There was 1 case of neo adjuvant Chemotheraphy, who received 3 cycles of TCF regimen underwent composite resection. All the composite resection cases underwentpost operative Adjuvant chemoradiotheraphy.

Among the 38 composite rections, 24 cases reconstruction done with Regional flaps (PectoralisMajor Myocuteneous(PMMC)flap,Deltopectoral, Nasolabial,and Forehead flaps ).In 14cases Free Flap reconstruction were done of which, 8 Free fibular Flaps, 4 Radial Forearm free flap , 1 Lateral Thigh flap and 1 Lateral forearm free flap were done .The most common recipient vesselfor arterialanastamosis in free flaps was Facial / Superior Thyroid artery.

Among the various Surgical incisions used for Oral cancer composite resection in 38 cases, Shoebeinger's incision remained the most common approach used in 26 cases. 4 cases underwent with lateral utility, and Visor flap. The 8 cases done with Modified Shoebeinger incision, wherein the vertical component is replaced by lower skin crease curvilinear horizontal modification. There were 24 segmental mandibulectomies, 3 Bite Resection with segmental mandibulectomies and 3 cases of Marginal mandibulectomies done with shoebingers incision, similarly 6 cases, 1 and 1 respectively done with modified shoebinger's incision.

Of late , 8 cases of composite resection with comprehensive neck dissection we have done with modification of Shoebinger's vertical limb to horizontal curvilinear lower skin crease incision( Modified shoebinger). In this approach, raising horizontal flaps/ skin bridge in lower neck should be meticulous with good retraction, Accessory $\mathrm{N}$ to be identified with careful dissection and preservation at erb's point \& Anterior border of trapezius. The skin bridge should be lifted with gauze straddling across for Level III, IV and V dissection. In our experience, inthe initial first case SAN got injured but the latter 7 cases, it is identified and preserved. Good traction, and countertractions are needed for proper exposure of the level III- V lymph nodal dissection. . The nodes at all levels
I to $\mathrm{V}$ can be done with good exposure, avoiding nerve injuries especially Accessory nerve with Modified Shoebinger incision. The nodal yield with this approach were in the range of 14 -26( Average 20) compared to 16- 28 (Average 22) in the regular cases, indicating acceptable standard clearance.All the 8 cases had margins negative resection and good wound healing.

The complications like primary \&secondary hemorrhage observed in $1 \& 2$ cases respectively,were managed appropriately to stabilize the patient. Of the two reactionary hemorrhage cases, 1 case was observed in Modified Shoebinger incision case which on re-exploration showed venous bleed from supra clavicular region, which was ligated.No wound dehiscence or infection ensued and wound healed with supple scar. Wound dehiscence in 2 cases, was observed at trifurcation of Shoebingers incision which healed with secondary intention resulting in hypertrophic scar ultimately an ugly contracture of which we would like to highlight that none of them are due to poor surgical approach. About 6 cases developed scar contracture out of which 5 were seen in the vertical part of the shoebingers incision for neck dissection. Among the 10 cases that had Modified shoebingersincision for neck dissection ,none had scar dehiscence or contracture during our 12 months of follow-up period. Wound dehiscence was noted at trifurcation of Shoebingers, which healed with secondary intention.

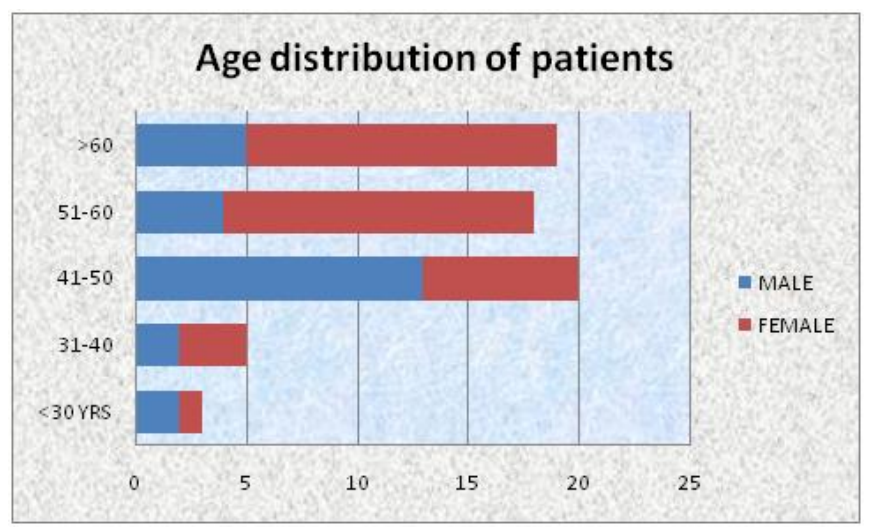

Figure 1: Age Distribution

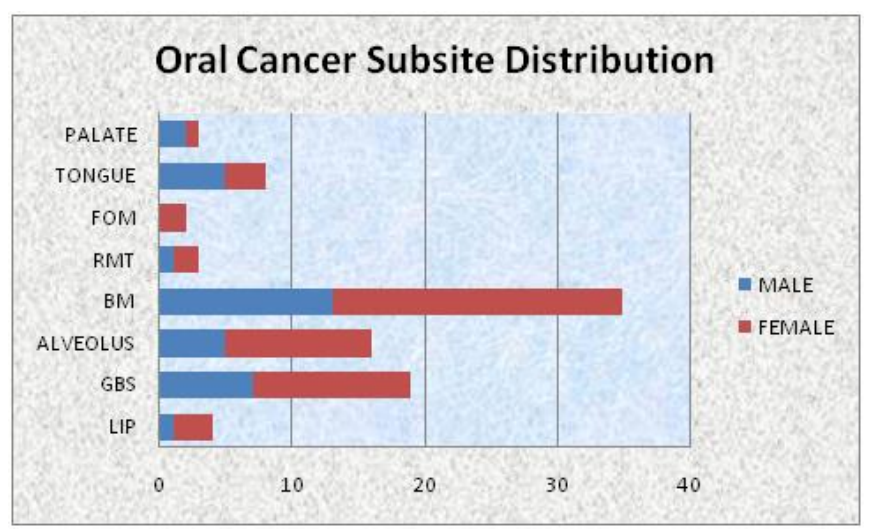

Figure 2: Subsite 
Narasannaiah of Ramesha: Impact of Incisian an Outcame in Campasite Resections of Oral Cancer

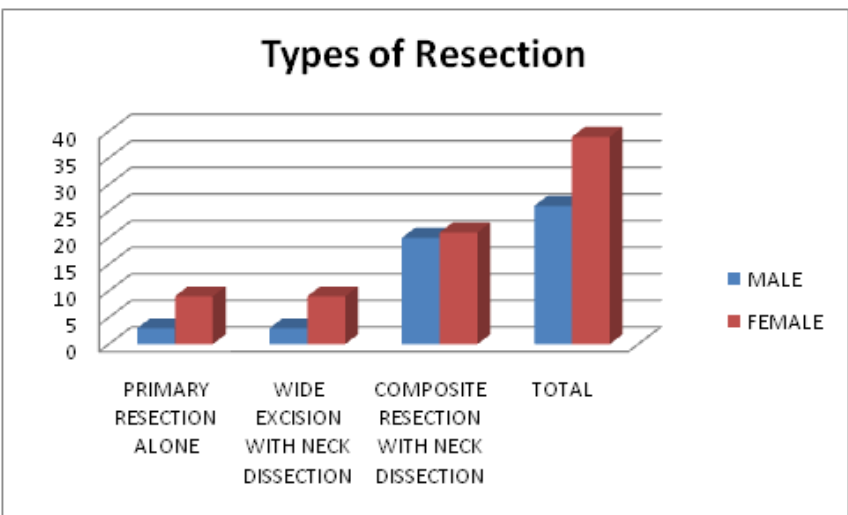

Figure 3: The types of resection done for oral cancers.

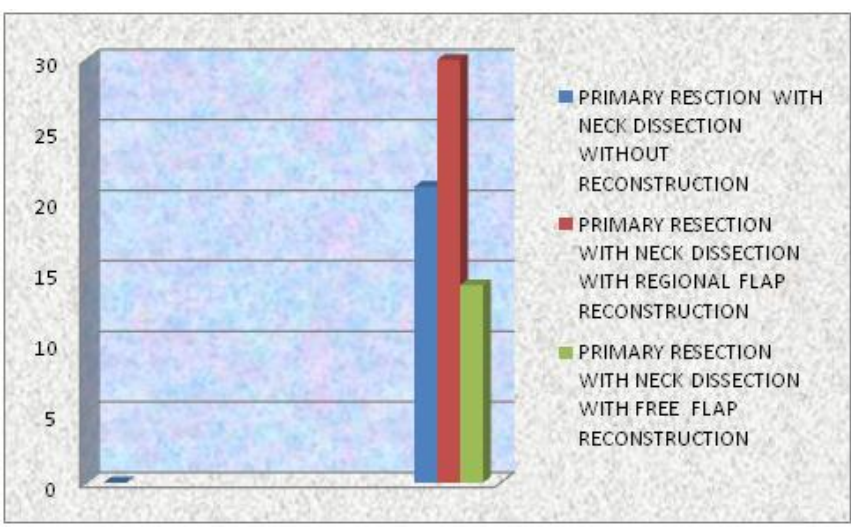

Figure 4: Various types of Reconstruction after resection

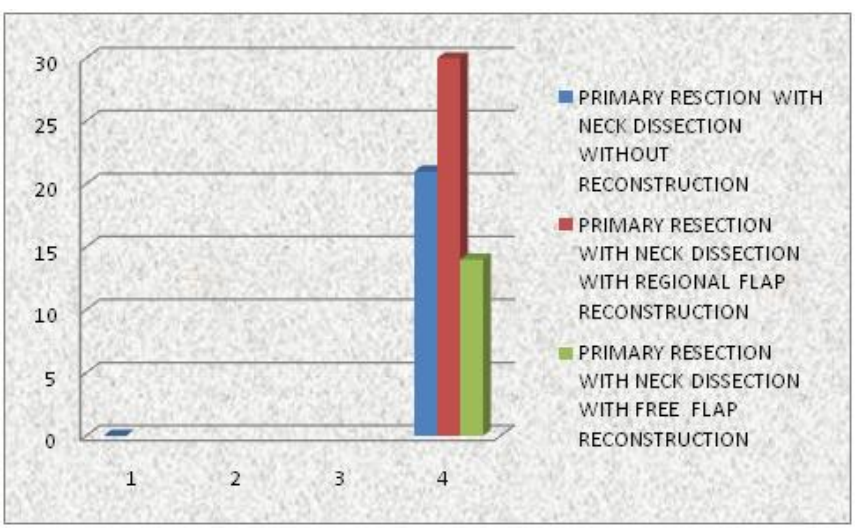

Figure 5: Types Of Reconstruction

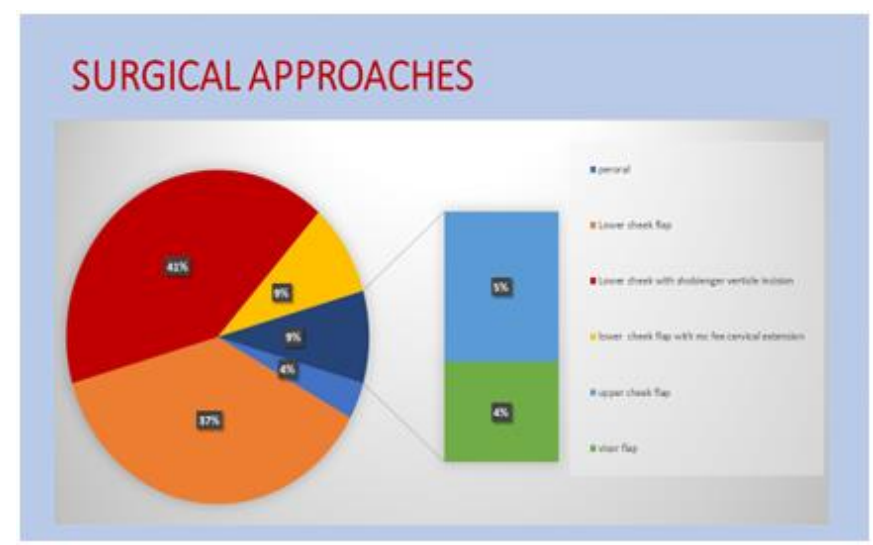

Figure 6: Surgical approaches
Table 1: Clinical Findings

\begin{tabular}{|l|l|l|}
\hline Number of Cases & $\begin{array}{l}\text { Lower Cheek } \\
\text { Flap With } \\
\text { Shoebinger's } \\
\text { Incision }\end{array}$ & $\begin{array}{l}\text { Lower Cheek Flap } \\
\text { With Modified } \\
\text { Shoebingersincision }\end{array}$ \\
\hline Total Number Of Cases & 26 & 8 \\
\hline $\begin{array}{l}\text { Number Of Cases With Wound } \\
\text { Dehiscence }\end{array}$ & 2 & 0 \\
\hline $\begin{array}{l}\text { Number Of Cases With Scar } \\
\text { Contracture }\end{array}$ & 5 & 0 \\
\hline Nodal Harvest(range) & $16-28$ & $14-26$ \\
\hline $\begin{array}{l}\text { Margin status of Primary } \\
\text { resection } \\
\text { 1.Negetive }\end{array}$ & & \\
2. Positive & & \\
\hline
\end{tabular}

\section{Discussion}

Among the various surgical approaches used for Oral cancer resection, the Lower cheek flap with Shoebeinger's vertical limb extension of incision for neck disection remained the most common approach used in $41 \%$ cases, Next being Lower cheek flap alone and others being Visor flap, upper cheek flap and per oral approach.With the lower cheek flap with midline lip split, resection of the any oral subsite primary can be done with adequate margin of clearance and healing is better with minimal scaring. Most of the regional flaps can be combined with lower cheek flap. The drawback of this lower cheek flap is, reaching level IV and V lymph nodal groups, especiallyamong long neck individuals, also pulling up the PMMC flap through the long tunnel compress the flap pedicles jeopardizing viability of the flap. Hence, the Shoebinger'svertical extension done from the lower cheek flap gives good exposure of level IV \&V lymph nodes dissection, along with narrowing down the skin tunnel. But the issue with this vertical extension is presence of trifurcation, which may lead to wound dehiscence. Also linear scar gives ugly look and hypertrophy of scar leads to contracture causing difficult lateral rotationmovement of neck .

Of late, we have started using Modified Shoebingerincision for dissection of Level IV \& V cervical lymph nodes, with curvilinear lower skin crease neck incision instead of vertical component. With this extension we can do good clearance of lower cervical lymph nodes, along with pulling up of the PMMC Flap to oral cavity for reconstruction.We have done about 8 cases with the modified Shoebinger incision (with horizontal Mc fee extension) for composite resection, neck dissection and reconstruction with good exposure for level IV \& V Lymph nodal clearance .The traction and retraction must be done with extra strength for proper visualization of neck anatomy and dissection.The Extent of primary dissection likeComposite, Bite resection and Segmental / marginal Mandibulectomy, can be done with this modified shoebingers incision with good negative margins. The horizontal Mc Fee extension being alongLangerhan's lines, allows good healing with thin scar without any contracture is observed.The vertical scar of shoebingerincision can be avoided with this modification of horizontal Mc fee modification for lower cervical lymphnodedissection, flap reconstruction and good cosmetic scar. 


\section{Conclusion}

Surgery isthe mainstay of treatment for local and locally advanced operable oral Cancer in all the subsites. There are various Surgical incision described for resection of oral Cancer based on the subsite, extent of resection, combining neck dissectionand need of reconstruction. The majority of cases in Indian scenario are locally advanced operable oral cancers ,necessitating composite resection and reconstruction can be done with Modified Shobeinger incision, for better exposure, sound oncological clearance and good cosmesis.

\section{References}

1. Ferlay J, Bray F, Pisani P, Parkin DM. GLOBOCAN 2002. Cancer incidence, mortality and prevalence worldwide. IARC CancerBase. 2004;5.

2. Petersen PE. Strengthening the prevention of oral cancer: the WHO perspective. Community dentistry and oral epidemiology. 2005 Dec;33(6):397-9.

3. Shah JP, Gil Z. Current concepts in management of oral cancersurgery. Oral oncology. 2009 Apr 1;45(4-5):394-401.

4. Shah JP. Surgical approaches to the oral cavity primary and neck. International Journal of Radiation Oncology* Biology* Physics. 2007 Oct 1;69(2):S15-8.

5. Press CR. Stell\&Maran's textbook of head and neck surgery and oncology. CRC Press; 2011 Dec 30.

6. Tubachi J, Jainkeri V, Gadagi V, Gunari P. Surgical incisions: Balancing surgical and cosmetic outcomes in head and neck oncosurgery. Otorhinolaryngology Clinics: An International Journal, May â $€$ “August. 2013 May;5(2):47-50.

Copyright: (C) the author(s), 2019. It is an open-access article distributed under the terms of the Creative Commons Attribution License (CC BY 4.0), which permits authors to retain ownership of the copyright for their content, and allow anyone to download, reuse, reprint, modify, distribute and/or copy the content as long as the original authors and source are cited.

How to cite this article: Narasannaiah AH, Ramesha KT. Impact of Incision on Outcome in Composite Resections of Oral Cancer. Acad. J Surg. 2019;2(2):48-51.

DOI: dx.doi.org/10.21276/ajs.2019.2.2.13

Source of Support: Nil, Conflict of Interest: None declared. 